|| ISSN(online): 2589-8698 || ISSN(print): 2589-868X || International Journal of Medical and Biomedical Studies

Available Online at www.ijmbs.info

PubMed (National Library of Medicine ID: 101738825)

Index Copernicus Value 2018: 75.71

Original Research Article

Volume 3, Issue 5; May: 2019; Page No. 82-88

\title{
PTM AND CELL CYCLE GATING MECHANISMS DEVIATED FOR PROGRESSION OF CANCER
}

\section{Eswari beeram}

Assistant Professor, Sree Vidyanikethan Degree College, A.P, India

Article Info: Received 20 April 2019; Accepted 14 May. 2019

DOI: https://doi.org/10.32553/ijmbs.v3i5.245

Corresponding Author: Eswari beeram, Assistant Professor, Sree Vidyanikethan Degree College, A.P, India

Conflict of interest: No conflict of interest.

\begin{abstract}
:
Post translational modifications like phosphorylation, Glycosylation and ADP ribosylation serves as biomarkers and are mainly involved in regulation of signalling pathways, cell polarity and cell cycle progression. So, this review helps in finding the biomarkers in understanding of cancer genome and also the deviations observed in gating mechanisms. Mucin 3 is mainly involved in EMT transition and Phosphorylation is also required for effective complex formation between catenin and cadherin. Hyaluron acts as medium for the tumors cells and aids in their movement and responsible for metastatic development. Epigenetic modification like methylation is helpful for cancerous genome to develop additional mutations for survival of the genome.
\end{abstract}

Key words: Cyclin D, PTMs, Gating, Glycosylation, Phosphorylation.

\section{Introduction}

Post translational Modifications are generally necessary for the functionality of proteins and in the direction to its location for example attachment to plasma membrane but some of the PTMs acts as biomarkers and is necessary for survival of certain cancers like breast cancer. In which phosphorylation and glycosylation and ADP ribosylation was discussed in detail here. ADP ribosylation was mainly done by PARP and in humans the gene that encodes this enzyme was located on chr 1 and acts as site for mutation in Fanconi anemia and responsible for pathophysiology in case of type I diabetes. This protein causes PTM of nuclear proteins exclusively compared to cytoplasm. Enzyme shows high level expression in lymph node and interacts with proteins like gp 120, nef, tat,vpu, vpr, integrase and retropepsin of HIV. It also interacts with topo I and Med 6 in addition to NAD+ and ADP- Ribose

Phosphorylation normally plays a crucial role in regulation of enzymes and its role in tumor transformation occurs through regulation of pathways like MAP kinase which is necessary for proliferation and may regulate negatively in case of pathways involved in differentiation and ECM modification. One of such example is catenin and cadherin interaction. Catenin and cadherin complex is necessary for maintainance of cell polarity and regulation of growth through formation of adherens junctions before to the incorporation of wnt signalling pathway and plays a important role in cell polarity at least. Phosphorylation is necessary for increasing affinity between the catenin and cadherin to form complex which is regulated by endocytosis also.

Similarly irregular glycosylation also may be responsible for change of polarity in cells for example Mucin - 3 is responsible for EMT transition and finally the tumor metastasis. Cell cycle arrest is the excellent gating mechanism that protects and prevent the unwanted cells like those having aberrations in genome to exit the cell cycle until it is corrected, for example like DNA damage. So many proteins are required for gating mechanism especially at check points. Over past decades so much of research on cell cycle and the proteins that control was done and the proteins involved was successfully identified. Major regulation at cell cycle occurs at CDK- cyclin complex formation and activation of complex by proteins like CDKKs.

In addition to above discussed factors epigenetic modifications also plays a major role in tumor development and progression. 


\section{PTMs and cancer:}

PARP (Poly (ADP Ribose) Polymerase role as ADP ribosylation factor was known from decades. But its role in development and preventing cancer was known recently. PARP1 is mainly involved in cell cycle checkpoint vigilance response, cell Proliferation and NHEJ repair after DNA damage. Some of the key points about PARP include its regulation of some events in the cell through ADP ribosylation. Some of the epigenetic changes like methylation events by methylases is regulated by ADP ribosylation. Methylation normally occurs during replication inorder to distinguish the newly synthesising strand from parent strand. Hyper methylation leads to abrupt response to repair of DNA if there is any damage where as hypomethylation prevents the recruit of repair proteins which in case of cancer cells causes apoptosis of the cell.

In case of cell cycle the PARP1 binds with that of p53 and involved in regulation of $\mathrm{G} 1$ phase cellular checkpoint leading to apoptosis if in case there is any genetic aberrations like hyperploidy and hypoploidy. Where as cancer cells with P53-/-are resistant to this response which indicates that $A D P$ ribosylation in case of p53 is necessary for the function of this protein which has to be proved. PARP 1 is also necessary for activity of NOS and it is proved that NO is required for cell proliferation. NAD is the main effector for ADP ribosylation as it acts as donor for ADP ribose group, so NAD depleting drugs induces tumors but the major question is opposite response is seen in case of methylating and ethylating agents, regarding the development and progression of carcinogenesis. Various mouse models like SCID mice in which gene corresponding to PARP1 was defective caused T- cell lymphoma but not the B cell lymphoma which proves that NAD promotes VDJ recombination in SCID mice which may be the one of reason for it.

The protein PARP is mainly involved in NHEJ repair but not BER but the response to oxidative stress leading to inflammation primarily and further progression to cancer increases in PARP-/- animals. By this we can explain how the protein modifications plays unique role in transforming normal cells to cancer cells.

Mucins are the glycans with tandem repeats of Glc NAc at ser/thr residues and are expressed mainly in apical membrane of cells. In cancerous cells mucin is expressed in the basal membrane and released in to the blood stream forms basis for EMT and also metastasis (Yang HL, Bin \& Teng et al 2017). Tumor cells express TAg or $\mathrm{Tn} \mathrm{Ag}$ in the blood stream and can be targeted to increase prognosis which is under study now. E- selectin is one of the glycated protein that is over expressed in cancer cells. Its over expression in blood cells causes arrest of movement of blood cells in stream and causes EMT in erythrocyte leukaemias.

In EMT most of the markers like cytokeratin and vimentin are the hall markers of EMT was expressed in the tumors and it was found that the markers that are expressed are specific to tumor type (Lange CA et al 2014).

Mucin -3 was also found to be the major protein required for EMT transition in addition to others as explained above it causes deposition of tumor cells from lung to liver and is characterised with hepato cellular carcinoma.

Phosphorylation is one of the post translational modification to studied in relation to cancer as many signalling pathways like MAP kinase, tyrosine kinase, catenin - cadherin and CDK- cyclin activation are regulated through phosphorylation and promotes in the way to development of carcinogenesis if deregulated. MAP kinase is involved in proliferation and tyrosine kinases are the main effective activators of receptors on the surface which is intrinsic to the receptor up on ligand binding. Whereas catenincadherin complex is necessary for extra cellular matrix maintainance (Nelson WJ. 2008, Dickinson DJ et al 2011, Reynolds AB. 2011) and where as CDKs are the main components of cell cycle whose complete activation requires phosphorylation.

Phosphorylation plays major role in cell proliferation which can be supported by un regulated activation of PI3 kinase, PKC and c-Raf without activating the upstream targets, phosphorylation of protein phosphatase 2a is responsible for carcinogenesis (Ishii $Y$ et al 2017).

\section{Phosphorylation and its role in Reproductive cancers:}

Breast cancer is one of the well known reproductive cancer till now and found to be resistant to most of the drugs like tamoxifen. So, up to now, mainly cell signalling is considered as the drug targets of the cancer. However in addition to cell signalling, Phosphorylation events in cell signalling proteins like smad3 by TGF- $\beta$ known now leading to the tumors in breast . Arrest of phosphorylation of smad 3 linker 
lead to progression of breast cancer compared to the mutation to phosphorylation events of smad 3 tail.

Ovarian cancer is other type of reproductive cancer in which $\beta$ - catenin is dysregulated leading to ovarian endometrioid adenocarcinoma which relates to histological aspect of ovarian cancer as in the review of Gatcliffe TA et al 2008 and Wnt signalling in addition to gene mutations is found to be the most dysregulated signalling pathway in ovarian cancer.

Protein kinases are greatly enhanced in testes during spermiogenesis and colocalisation of protein kinases along with golgi markers are crucial for sperm production so uncontrolled phosphorylation events may leads to tumors in testes. In addition to testicular cancer, Prostate cancer also requires phosphorylation of certain proteins like PCNA. PCNA is normally required for DNA replication in proliferating cells. Phosphorylation of PCNA at Y211 is required for its activity and inhibition of it is used to treat prostate cancer which is resistant to refactory hormonal therapies.
One of the well known post translational modifications is glycosylation of proteins and enzyme which interplays the crew is $\mathrm{N}$ - acetyl glucosamine transferase or Mgat 5. Glycation of proteins should be proper and extensive glycation or truncated glycation is a hall mark of many tumors which showed positive reaction with phytohemeagglutin with Mgat5 +/+ associated tumors (Cha HM et al 2017). Mgat5 induces lattice formation of glycans with galectin, and recognition of fucose residues by $\mathrm{E}$ selectin is associated with FUT 8 proved by prediction in some of the lung cancers. Where as mgat 4 and mgat 3 action is entirely reverse in case of tumor progression and metastasis. Mgat 3 is mainly involved in the addition of Glc NAC residues to form branched structure where as Mgat4 is involved in addition of sialic residues to the erythropoietin during fetal embryogenesis. Erythropoietin was known to show anti apoptotic activity and prevent carcinogenesis (Lombardero $\mathrm{M}$ et al 2011).

Table: 1 Post Translational Modifications of proteins and their relation to cancer. Ref: OCT 4 (Cho Y et al 2018), PRP 31 (Tung CH et al., (2017), PDL- 1 ( Hsu JM et al (2018), H2A, H2B,H3 ( Khan SA et al 2015), PKM2 (An S et al 2018, Prakasam G et al 2018), Vimentin ( Shi AM. 2016), H4 ( Tryndyak VP et al 2006).

\begin{tabular}{|c|c|c|c|}
\hline 1. & $\begin{array}{l}\text { Epigenetic } \\
\text { modifications }\end{array}$ & Position of modifications & Cancers containing modifications \\
\hline & $\begin{array}{l}\text { Histones } \\
\text { Methylation } \\
\text { H3 } \\
\text { H3 } \\
\text { H4 } \\
\text { H2 A } \\
\text { H2B }\end{array}$ & $\begin{array}{l}\text { Lys27, Lys36, Lys79 } \\
\text { Arg 2, Lys9, Lys } 14 \\
\text { Arg3, Lys 8, Lys } 12 \\
\text { Lys9, Arg12 } \\
\text { Lys5 }\end{array}$ & $\begin{array}{l}\text { Glioblastoma } \\
\text { Colorectal cancer } \\
\text { Breast cancer } \\
\text { colorectal cancer } \\
\text { Lung cancer }\end{array}$ \\
\hline \multirow[t]{6}{*}{2.} & $\begin{array}{l}\text { Post Translational } \\
\text { Modifications }\end{array}$ & Position of modifications & Cancers containing modifications \\
\hline & $\begin{array}{l}\text { Ubiquitylation } \\
\text { OCT4 } \\
\text { PD L-1 } \\
\text { PKM2 }\end{array}$ & $\begin{array}{l}\text { Lys284 } \\
\text { Not known yet } \\
\text { Lys186, Lys206 }\end{array}$ & $\begin{array}{l}\text { Breast cancer } \\
\text { Not known yet } \\
\text { Lung cancer }\end{array}$ \\
\hline & $\begin{array}{l}\text { Phosphorylation } \\
\text { NFIP1 }\end{array}$ & $\begin{array}{l}\text { Tyr42,Tyr19, Ser166, Ser46, } \\
\text { Ser28Ser75,Ser82,Tyr52,Tyr172,Thr } \\
\text { 167,Ser 59 }\end{array}$ & Breast cancer \\
\hline & PRP 31 & $\begin{array}{l}\text { Thr138,Tyr135, Ser119,Ser213, } \\
\text { Ser277, Tyr273,Thr 258, Thr312 } \\
\text { Tyr318,Ser311, Ser307 }\end{array}$ & Breast cancer \\
\hline & PKM2 & $\begin{array}{l}\text { Tyr105, Tyr83, Tyr148, Tyr175, } \\
\text { Tyr 370, Tyr390,S37, S202 }\end{array}$ & Breast cancer \\
\hline & Vimentin & Ser6, ser38 and Ser50 & Breast cancer \\
\hline
\end{tabular}




\section{Major regulatory proteins in cell cycle and cancer:}

Another important aspect is the overall regulation of cell cycle in cancer subjects. Cyclin $E$ is required for transition of cell cycle from $G 1$ to $S$ phase. It also phosphorylates P27 kip1 which is an inhibitor of cyclin $D$ and targets it for degradation. So it results in DNA duplication. Recent updates on cell cycle including cyclin $\mathrm{E}$ over expression, leads to decrease in overall survival in normal patients and also in case of breast cancer. But in case of oral cancer the CCND1A870 G (cyclin D) polymorphism is responsible for the cancer in asians and has proved the $A G$ heterogeneity as the dominant phenotype (Wang W et al 2013) Similarly CCND1 G 870 A polymorphism is also responsible for chance of lung cancer with $95 \%$ in case of AG heterogeneity (Liu J et al 2012) as explained above.

Cell cycle mainly progress depending on the availability of Cyclins and CDKs. CDK- Cyclin complex is fully activated by phosphorylation by cdk kinase and unless this post translational modification of protein occurs, the kinase activity of cdks will not be targeted to respect substrates of cell cycle. So, the cdk kinase may be targeted as cancer therapeutics and there is no reports regarding to this protein in the direction of cancer.

In most of the cancers especially breast cancer cells stroma plays an important role in carcinogenesis. Hyaluron acts as ligand to cd44 and the complex activates pathways like MAP kinase, antiapoptotic pathways and PI3/ Akt signaling pathways. It also phosphorylates epidermal growth factor receptor also and Hyaluronan acts as medium for the movement of cells between tissues. In some of the cancers like melanoma sialic acid residues acetylation are increased at position 0-9 were as the decrease is seen with colon carcinomas. Micro environment remodellation, inflammation and fragmentation of Hyaluronan is responsible for tumor progression and invasion which starts up by secretion of inflammatory cytokines (Schwertfeger KL et al 2015) by tumor tissue.

Normally cells are under continous vigilance of the genome in the direction of regulation of which has to divide and which has to not. The major check point is at $\mathrm{G} 1$ phase which is mainly regulated by $\mathrm{Rb}$ protein which binds to $\mathrm{E} 2 \mathrm{~F}$ and regulates its activation and inhibition (Zhao F et al 2001). The activation of E2F leads to passage of gating through $\mathrm{G} 1$ phase and commitment to DNA duplication. The protein mainly activates DNA polymerase and some of the genes like Cyclin D1 mainly show elevated gene expression in case of brain tumors.

\section{Epigenetic modifications in cancer:}

Epigenetic modifications of the cell cycle genes can lead to hypermethylation of the respective gene by converting the euchromatin to heterochromatin and finally leading to gene silencing. For example SOX 17 is one of the key gene involved in development of endoderm in the colon and mutation of it causes manipulations in extracellular matrix composition as it inhibits wnt signalling by binding to $\beta$ - catenin and prevents the signalling cascade. Now there are reports available about the key role of SOX17 in cell fate of primordial germ cells during early stage of embryonic development (Irie $\mathrm{N}$ et al 2015).

Hic-1 is one of the major gene that regulates embryonic stem cell development through its transcriptional inhibitors SIRT1 and atonal. TCGA 2008 is the one of the upcoming project going on now to understanding the genome of cancer cells inorder to understand the key salient features of gene expression and assessment of genome integrity in cancerous cells. Hypermethylation induced cancer gene (Hic-1) causes hypermethylation of genes leading to gene silencing. So, using this property of Hic -1 can be useful in cancers showing increased expression of stem cells leading to carcinogenesis. 
Table: 2 Cell cycle deviation and expression level of cell cycle proteins.

Ref: USP 18, SKP2 (Vuillier F et al 2019), STK31 (Kuo PL et al 2014), CksHs1, P45 SKP2 (Mongay L et al 2001), Hog1 SAPK(Zapater $M$ et al 2005), A Proliferation inducing ligand ( APRIL)- (Quinn J et al 2011), Gcr A from caulobacter vibrioides (UniProtKBAOAOH3C9J4 (AOAOH3C9J4_CAUVN)

\begin{tabular}{|l|l|l|}
\hline Name of cell cycle regulator & $\begin{array}{l}\text { Expression level in cancer } \\
\text { cells }\end{array}$ & Normal function of the protein \\
\hline USP18 & Increased & Stabilises SKP2 \\
\hline $\begin{array}{l}\text { SKP2 (S- phase kinase associated } \\
\text { protein 2) }\end{array}$ & Increased & Cell cycle progression \\
\hline Cyclin D1 & Increased & G1//S phase progression \\
\hline STK31 (ser/Thr kinase 31) & Increased & Regulates spindle assembly check point \\
\hline Gcr A from caulobacter vibrioides & Not known & $\begin{array}{l}\text { Cell cycle regulation (step of regulation is } \\
\text { unknown) }\end{array}$ \\
\hline CksHs1 & decreased & Inhibits CDK2 \\
\hline P45 SKP2 & Increased & Inhibits CksHs1 \\
\hline Hog1 SAPK & decreased & Causes cell cycle arrest \\
\hline $\begin{array}{l}\text { A Proliferation inducing ligand } \\
\text { ( APRIL) }\end{array}$ & increased & Cell cycle progression in presence of cyclin D2 \\
\hline
\end{tabular}

Hic 1 represents one of the tumor suppressor protein (Szczepny A et al 2018) which also regulates genes involved in cell cycle control and stress. Its main target includes TLR 2 which activates NF- kB pathway and ablation of the gene leads to increased $\mathrm{Tlr}$ 2leading to activation of NF- kB pathway and many colon cancers with Hic1-/- mutation.. As discussed above inflammation plays an important role in cancer progression and metastasis through manipulation of stroma in the tissues.

In previous era Hic 1 is treated as a transcriptional repressor but recent reports on the gene described the role of the gene in development, function and survival of iT reg cells. Hic1 is mainly responsible for the suppressive function of iTreg cells so, loss of the gene function directly affect the function of iTreg cells. Hic 1 is also involved in maintaining chromosomal integrity (Janeckova L et al 2015) under replicative stress and loss of gene leads to micropapillary phenotype with more susceptibility to adenocarcinomas. Hic 1 defeciency leads to cell cycle arrest, premature senescence and cell death.

Another Protein namely ARF also effects cell cycle progression in positive and negative manner. From the new reports ARF causes G1 phase progression compared to previous reports which supports that it inhibits cell cycle G1 phase progression (Pare R et al
2016). ARF is one of the senescence marker studied in breast cancer patients and found as one of the useful prognostic marker.

By this we can conclude that post translational modifications (PTM) and cell cycle arrest promoting genes improves genome integrity in higher animals and explains how deregulation from normal leads to carcinogenesis and also in understanding the cancer cell genome.

\section{Discussion:}

Cancer is one of the major disorder prevailed in both developed and developing countries. Considering the our constrain we focus on post translational modifications and genes that cause cell cycle arrest in normal and cancerous tissues and understanding the mechanism at both gene level and also at the molecular level. Mainly phosphorylation and glycosylation and unoftenly ADP ribosylation can leads to more disastrous disorder. ADP ribosylation by PARP requires cofactor NAD+ which supplies ADP ribose necessary for PTM and should be maintained in levels in order for proper function of the enzyme. Mainly in cancerous tissues due to elevated oxidative stress there is depletion of NAD+ and also NADP+ as these are reduced by the anti oxidant enzymes and eventhough sources are available in the system but 
how the enzyme works in is a question supported by other survival mechanisms.

Another important modification is phosphorylation which is responsible for deregulation of signalling pathways as explained in section 1 . When coming to the genes involved in cell cycle arrest major genes has already covered so far and where as in case of epigenetic modifications include Hic 1 and due to cellular senescence is by ARF and so on.

\section{References:}

1. An S, Huang L, Miao P, Shi L, Shen M, Zhao X, Liu J, Huang G. 2018. Small ubiquitin-like modifier 1 modification of pyruvate kinase M2 promotes aerobic glycolysis and cell proliferation in A549 human lung cancer cells.OncoTargets and Therapy. 11: 2097-2109.

2. Cha HM, Lim JH, Yeon JH, Hwang JM, Kim DI. 2017.Co-overexpression of Mgat1 and Mgat4 in $\mathrm{CHO}$ cells for production of highly sialylated albumin-erythropoietin. Enzyme Microb Technol.103:53-58.

3. Cho Y, Kang HG, Kim SJ, Lee $S$, Jee $S$, Ahn SG, Kang MJ, Song JS, Chung JY, Yi EC et al. 2018. Post-translational modification of OCT4 in breast cancer tumorigenesis. Cell Death \& Differentiation. 25: 1781-1795.

4. Dickinson DJ, Nelson WJ, Weis WI 2011. A polarized epithelium organized by $\beta$ - and $\alpha$ catenin predates cadherin and metazoan origins. Science. 331 (6022):1336-9.

5. Gatcliffe T.A, Monk B.J, Planutis K, And Holcombe R.F. 2008. Wht signaling in ovarian tumorigenesis. Int J Gynecol Cancer. 18(5): 954962.

6. Hsu JM, Li CW, Lai Y J, and Hung M C. 2018. Posttranslational Modifications of PD-L1 and Their Applications in Cancer Therapy. Cancer Res. 78(22):6349-6353.

7. Irie N, Weinberger L, Tang WWC, Kobayashi T, Viukov S, Manor YS, Dietmann S, Hanna JH and Surani MA. 2015. SOX17 Is a Critical Specifier of Human Primordial Germ Cell Fate. Cell. 160(12): 253-268.

8. Ishii Y, Kuroda K, Matsushita K, Yokoo Y, Takasu S, Kijima A, Nohmi T, Ogawa K, Umemura T.
2017. Phosphorylation of protein phosphatase 2A facilitated an early stage of chemical carcinogenesis. Toxicol Appl Pharmacol. 336:7583.

9. Janeckova L, Pospichalova V , Fafilek B, Vojtechova M, Tureckova J, Dobes J, Dubuissez $M$, Leprince $D$, Baloghova $N$, Horazna $M$, et al. 2015. HIC1 Tumor Suppressor Loss Potentiates TLR2/NF-kB Signaling and Promotes Tissue Damage-Associated Tumorigenesis. Mol Cancer Res; 13(7):1139-48.

10. Khan SA, Reddy D, Gupta S. 2015.Global histone post-translational modifications and cancer: Biomarkers for diagnosis, prognosis and treatment?. World J Biol Chem.; 6(4): 333-345.

11. Kuo PL, Huang $Y L$, Hsieh, Lee JC, Lin BW, Hung LY. 2014. STK31 Is a Cell-Cycle Regulated Protein That Contributes to the Tumorigenicity of Epithelial Cancer Cells. PLOS ONE . 9 (3): 1-12..

12. Lange CA, Accogli G, Cremonesi F, Desantis S. 2014. Cell Surface Glycan Changes in the Spontaneous Epithelial-Mesenchymal Transition of Equine Amniotic Multipotent Progenitor Cells. Cells Tissues Organs. 200(3-4):212-26.

13. Liu J, Liao Q, Zhang Y, Sun S, Zhong C, Liu X. 2012. Cyclin D1 G870A polymorphism and lung cancer risk: a meta-analysis. Tumor Biology. 33(5): 1467-1476.

14. Lombardero M, Kovacs K, Scheithauer BW. 2011. Erythropoietin: a hormone with multiple functions. Pathobiology.78(1):41-53.

15. Mongay L, Plaza S, Vigorito E, Carles SP, and Vives J. 2001. Association of the Cell Cycle Regulatory Proteins p45SKP2 and CksHs1. The Journal Of Biological Chemistry.27(6): 2503025036.

16. Nelson WJ. 2008. Regulation of cell-cell adhesion by the cadherin-catenin complex. Biochem Soc Trans. 36(2): 149-155.

17. Pare R, Shin JS, Lee CS. 2016. Increased expression of senescence markers p14(ARF) and p16(INK4a) in breast cancer is associated with an increased risk of disease recurrence and poor survival outcome. Histopathology. 69(3):479-91. 
18. Prakasam G, Iqbal MA, Bamezai RNK and Mazurek S. 2018. Posttranslational Modifications of Pyruvate Kinase M2: Tweaks that Benefit Cancer. Front. Oncol. 8(22): 1-12.

19. Quinn J, Glassford J, Percy L, Munson P, Marafioti T, Justo MR, and Yong K. 2011. APRIL promotes cell-cycle progression in primary multiple myeloma cells: influence of D-type cyclin group and translocation status. BLOOD. 117(3):890-901.

20. Reynolds AB. 2011. Epithelial organization: new perspective on $\alpha$-catenin from an ancient source. Curr. Biol. 21 (11): 430-2.

21. Schwertfeger $K L$, Cowman $M K$, Telmer $P G$, Turley EA, and McCarthy JB. 2015. Hyaluronan, Inflammation, and Breast Cancer Progression. Front Immunol. 6: 1-12.

22. Shi AM. 2016. Vimentin and post-translational modifications in cell motility during cancer - a review. Eur. Rev. for Medical and Pharmacological Sciences. 20(12):2603-6

23. Szczepny A, Carey K, McKenzie1 L, Jayasekara WSN, Rossello F, Rajal AG, McCaw AS, Popovski D, Wang D, Sadler AJ, et al. 2018. The tumor suppressor Hic1 maintains chromosomal stability independent of Tp53. Oncogene. 37:1939-1948.

24. Tryndyak VP, Kovalchuk O \& Pogribny IP. 2006. Loss of DNA methylation and histone $\mathrm{H} 4$ lysine 20 trimethylation in human breast cancer cells is associated with aberrant expression of DNA methyltransferase 1, Suv4-20 h2 histone methyltransferase and methyl-binding proteins. Can. Biol \& Therapy 5:1, 65-70.

25. Tung $\mathrm{CH}$, Shueng $\mathrm{PW}$, Chu $\mathrm{Y} \mathrm{W}$, Chen $\mathrm{CW}$, Chen CY. 2017. Identifying Post-translational Modification Crosstalks for Breast Cancer. Journal of Computing Science and Engineering. 11(4), 111-120.

26. UniProtKB - AOAOH3C9J4 (AOAOH3C9J4_CAUVN)

27. Vuillier F, Li Z, Commere PH, Dynesen LT \& Pellegrini S. 2019.USP18 and ISG15 coordinately impact on SKP2 and cell cycle progression. Scientific Reports. 9:4066: 1-11.

28. Wang W, Zhao Y, Yang J, Lin B, Gu H, Cao X, Ge L. 2013. Cyclin D1 polymorphism and oral cancer: a meta-analysis. Mol. Biol. Reports.40(1): 87-95.

29. Yang HL, Bin \& Teng, Mujian. 2017. T-cell immunoglobulin Mucin-3 as a potential inducer of the epithelial-mesenchymal transition in hepatocellular carcinoma. Oncology Letters. 14: 5899-5905.

30. Zhao F, Vilardi A, Neely RJ, and Choi JK. 2001. Promotion of Cell Cycle Progression by Basic Helix-Loop-Helix E2A. Mol. and cellular biology. 21(18): 6346-6357.

31. Zapater M, Clotet J, Escote X and Posas F. 2005. Control of cell cycle progression by the stress activated Hog1 MAPK. Cell cycle. 4(1): 6-7. 